\title{
Immunohistochemical evidence of neuronal and glial differentiation in retinoblastoma
}

\author{
Ke-Ping Xu, Shang-Lian Liu, Chuo Ni
}

\begin{abstract}
Background-The study sought to investigate the histogenesis of retinoblastoma. Methods-One hundred specimens of retinoblastomas were examined along with those of 18 astrocytic gliomas and 15 medulloblastomas to compare similarities of glial differentiation in retinoblastoma and the two types of brain tumour. Employing avidin-biotin immunoperoxidase technique, antibodies were applied against neuron specific enolase (NSE), glial fibrillary acidic protein (GFAP), and S-100 protein (S-100).

Results-Most rosettes and fleurettes, and some undifferentiated cells in retinoblastomas were NSE positive, but GFAP and S-100 negative. GFAP and S-100 positive cells in retinoblastomas were detected mostly in well differentiated glial cells which were interpreted as reactive or nonneoplastic cells. Some of the GFAP and S-100 positive cells in retinoblastomas were defined as tumour cells that resembled neoplastic astrocytes in astrocytic gliomas and medulloblastomas. Conclusion-Retinoblastoma may arise from primitive bipotential or multipotential cells capable of neuronal and glial differentiation.
\end{abstract}

(Br f Ophthalmol 1995; 79: 771-776)

Retinoblastoma is the most common primary intraocular neoplasm in children. Its histogenesis has been disputed for more than a century. The view that retinoblastoma was a glioma of the retina was first proposed by Virchow in $1864 .^{1}$ Flexner subsequently described rosettes as the characteristic of a well differentiated form of the tumour, suggesting that retinoblastoma was a neurocytoma of the retina. ${ }^{2}$ However, Bailey and Cushing considered the undifferentiated retinoblastic cells to be the progenitor of the tumour. ${ }^{3}$ Previous electron microscopic study by Tso and associates demonstrated that retinoblastoma cells shared many features with normal retinal photoreceptors, indicative of their neuronal origin. ${ }^{4}$ The advent of immunohistochemistry makes it possible to detect neuronal and glial elements in situ. Immunohistochemical studies have proved that retinoblastoma may arise from neuronal or neuroectodermal cells, ${ }^{6-11}$ or from primitive stem cells devoid of any glial differentiation. ${ }^{1213}$ Astrocytes in the tumour were interpreted as being either reactive, in response to tumour growth and proliferation, ${ }^{14} 15$ or neoplastic, based on their distribution pattern and cytological features. ${ }^{15-18}$ Nevertheless, no agreement has been reached as to the existence of neoplastic glial cells in retinoblastoma.

In this histogenetic study we examined retinoblastomas along with astrocytic gliomas and cerebellar medulloblastomas in order to compare glial differentiation in retinoblastoma and the two types of brain tumour. We also determined relations between clinicopathological features and the expression of neuronal markers in a large retinoblastoma series.

\section{Materials and methods}

Formalin fixed and paraffin embedded tissues of 100 enucleated retinoblastomas, 18 astrocytic gliomas, and 15 medulloblastomas were randomly selected. Immunohistochemical staining was carried out by the avidin-biotin peroxidase complex method $(\mathrm{ABC})^{19}$ to detect the presence of neuron specific enolase (NSE), glial fibrillary acidic protein (GFAP), and S-100 protein (S-100).

Sections of $5 \mu \mathrm{m}$ were cut and mounted on clean gelatin coated slides. They were routinely deparaffinised in xylene and hydrated in an ethanol series. Each step was followed by washing with TRIS buffered saline (TBS, pH $7.6,0.05 \mathrm{M})$. Sections, except those stained for NSE, were treated with $0.05 \%$ trypsin for 20 minutes, the resulting digestion unmasking the antigen before immunohistochemistry. They were then incubated with $1 \%$ normal horse serum for 20 minutes to quench endogenous peroxidase activity. Anti-NSE (A589, Dako, CA, USA) and anti-GFAP (z334, Dako), as primary antisera, were diluted 1:1000 with TBS, while anti-S-100 (K524, Dako) gave best results in a 1:5 dilution. Primary antibody incubation was carried out in a moist chamber at $4^{\circ} \mathrm{C}$ overnight. Sections were then reacted with secondary antiserum (biotinylated goat anti-rabbit IgG, 1:200, Vector Laboratories, CA, USA) for 30 minutes and subsequently treated with the avidinbiotinylated peroxidase complex (1:100, Vector Laboratories) for 60 minutes. Sites of peroxidase activity were visualised by incubation with $0.3 \%$ hydrogen peroxide and freshly prepared 3,3 diaminobenzidine in TRIS buffer to generate the colour reaction. Slides were counterstained with haematoxylin and mounted after dehydration through graded ethanol and xylene.

Non-immune rabbit serum was introduced as a negative control to substitute anti-NSE, GFAP, or S-100 in equal dilution to the primary antisera. A portion of normal retina within some of the retinoblastomas was used as a positive internal control. Consecutive 
Table 1 Neuron specific enolase (NSE), glial fibrillary acidic protein (GFAP), and $S-100$ protein $(S-100)$ immunoreactivity in three types of tumours (\%)

\begin{tabular}{|c|c|c|c|c|c|c|}
\hline \multirow[b]{2}{*}{ Tumour } & \multicolumn{2}{|l|}{$N S E$} & \multicolumn{2}{|l|}{$G F A P$} & \multicolumn{2}{|l|}{$S-100$} \\
\hline & $N C$ & $N N C$ & $N C$ & $N N C$ & $N C$ & $N N C$ \\
\hline $\begin{array}{l}\text { Retinoblastoma } \\
\text { Astrocytic glioma } \\
\text { Medulloblastoma }\end{array}$ & $\begin{array}{l}57 / 100(57) \\
0 / 18(0) \\
1 / 15(6 \cdot 7)\end{array}$ & $\begin{array}{l}0 / 100(0) \\
2 / 18(11 \cdot 1) \\
3 / 15(20)\end{array}$ & $\begin{array}{c}2 / 100(2) \\
16 / 18(88 \cdot 9) \\
4 / 15(26 \cdot 7)\end{array}$ & $\begin{array}{l}77 / 100(77) \\
2 / 18(11 \cdot 1) \\
9 / 15(60)\end{array}$ & $\begin{array}{l}8 / 100(8) \\
1 / 18(5 \cdot 6) \\
1 / 15(6 \cdot 7)\end{array}$ & $\begin{array}{l}54 / 100(54) \\
0 / 18(0) \\
3 / 15(20)\end{array}$ \\
\hline
\end{tabular}

$\mathrm{NC}=$ neoplastic cells; $\mathrm{NNC}=$ non-neoplastic cells. The ratio indicates the number of positive cases in the total cases studied.

sections of both normal eye bulb and normal brain served as further positive controls.

In evaluating the staining results, we concentrated on the morphology of the cells and differentiating of neoplastic from non-neoplastic positivity. The $\chi^{2}$ test was applied and a level of $\mathrm{p}<0.05$ was accepted as of statistical significance.

\section{Results \\ Table 1 lists the results of immunohisto- chemical staining of three types of tumours. In retinoblastomas NSE positive cells were neo- plastic only, while GFAP or S-100 positive ones included both neoplastic and non-neo- plastic cells. We found only GFAP or S-100 positive tumour cells in astrocytic gliomas, whereas there were both NSE and GFAP or S-100 positive in the tumour cells of medullo- blastomas. Table 2 gives the expression of neuronal and glial markers in neoplastic cells of retinoblastomas.}

\section{NEURON SPECIFIC ENOLASE}

With polyclonal antiserum against NSE, outer and inner segments of photoreceptor cells

Table 2 Expression of neuron specific enolase (NSE), glial fibrillary acidic protein $(G F A P)$, and $S-100$ protein $(S-100)$ in neoplastic cells of 100 retinoblastomas according to histopathological type

\begin{tabular}{lllll}
\hline Histopathological type & $N$ & NSE (\%) & GFAP (\%) & $S-100(\%)$ \\
\hline Differentiated & 30 & $28 / 30(93 \cdot 3)$ & $0 / 30(0)$ & $5 / 30(16 \cdot 7)$ \\
Undifferentiated & 70 & $29 / 70(41 \cdot 4)$ & $2 / 70(2 \cdot 9)$ & $3 / 70(4 \cdot 3)$
\end{tabular}

$\mathrm{N}=$ number of cases; ratio indicates the number of positive cases in the total cases studied.

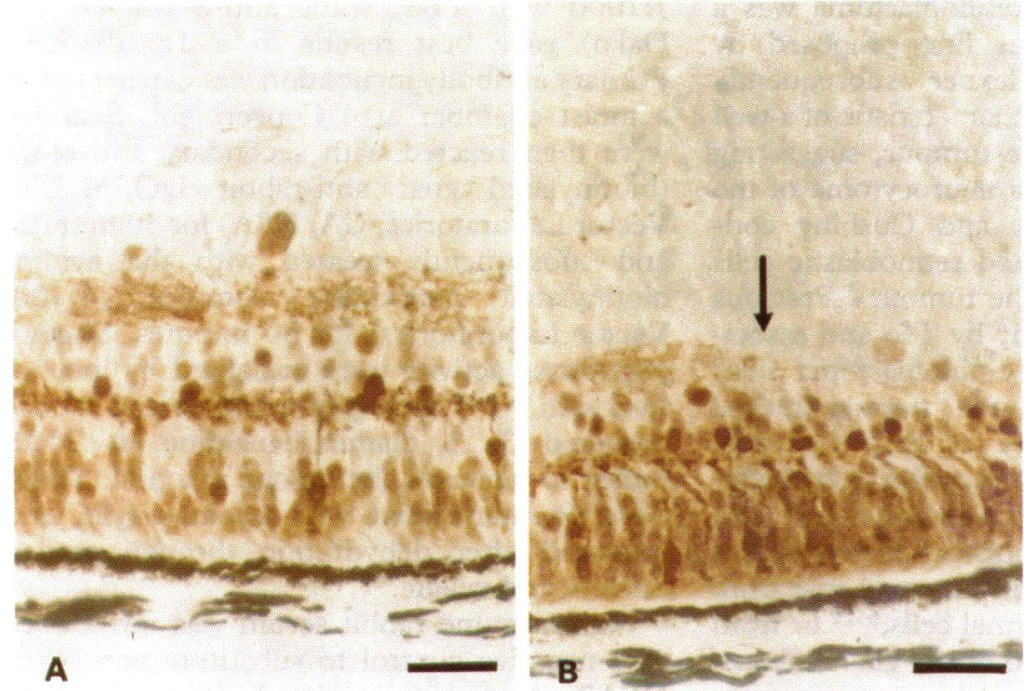

Figure 1 Neuron specific enolase (NSE) positive segments in the outer and inner nuclear layer, as well as ganglion cells of the normal retina $(A)$. A portion of normal retina stained with NSE (arrow) can be found remaining in the tumour mass (B) (haematoxylin and eosin, bar indicates $100 \mu \mathrm{m}$ ). in normal retina showed positive staining (Fig 1A). Typical rods and cones could be identified, and seemed to stain equally well. However, neurons in the outer nuclear layer stained more darkly than those in the inner nuclear layer. Most ganglion cell bodies in the nerve fibre layer were also NSE positive. Tumour overlying normal retina and partially retaining a normal nuclear layer can be recognised (Fig 1B). NSE positive cells were found in 28 of 30 differentiated retinoblastomas and in 29 of 70 undifferentiated ones. A variable number of cells forming Flexner-Wintersteiner and Homer-Wright rosettes, as well as fleurettes were NSE positive in cytoplasm and cell processes (Fig 2). In areas without appreciable rosette formation, there was a substantial variation in NSE staining intensity. These tumour cells included an entire cell spectrum ranging from well differentiated cells, that resembled photoreceptors in the outer nuclear layer and showed a tendency to form rosettes, to poorly differentiated small round cells (Fig 3). Vessels and glial cells all stained negatively. The overall proportion of retinoblastoma cells expressing NSE seemed to be lower in the tumour group of undifferentiated type, older age ( $\geqslant 4$ years), with choroidal invasion, and with metastasis to optic nerve $(\mathrm{p}<0.05)$. NSE expression was not related to sex or growth pattern (Table 3).

We found NSE negativity in all tumour cells of astrocytic gliomas and in most specimens of medulloblastomas. Only one medulloblastoma $(1 / 15,6 \cdot 7 \%)$ showed clearly demarcated NSE positivity where there were small round cells with no obvious rosette formation.

\section{GLIAL FIBRILLARY ACIDIC PROTEIN}

In normal retina or part of the retina not invaded by tumour cells, GFAP positivity was encountered in glial cells of the ganglion layer, such as perivascular astrocytes and satellite glial cells, and in Muller's cells which extended through almost the entire thickness of the retina. The optic nerve contained numerous GFAP positive cells, and this reaction served as an internal positive control.

In two of 100 retinoblastomas (2\%), we found some GFAP positive cells showing morphological similarity to the surrounding tumour cells, with a round hyperchromatic nucleus, scanty cytoplasm, and a few short thick processes (Fig 4A). The GFAP positive areas were distributed randomly throughout the undifferentiated areas of the tumour and were not associated with blood vessels. In some cases other GFAP positive cells were found surrounding blood vessels, with 

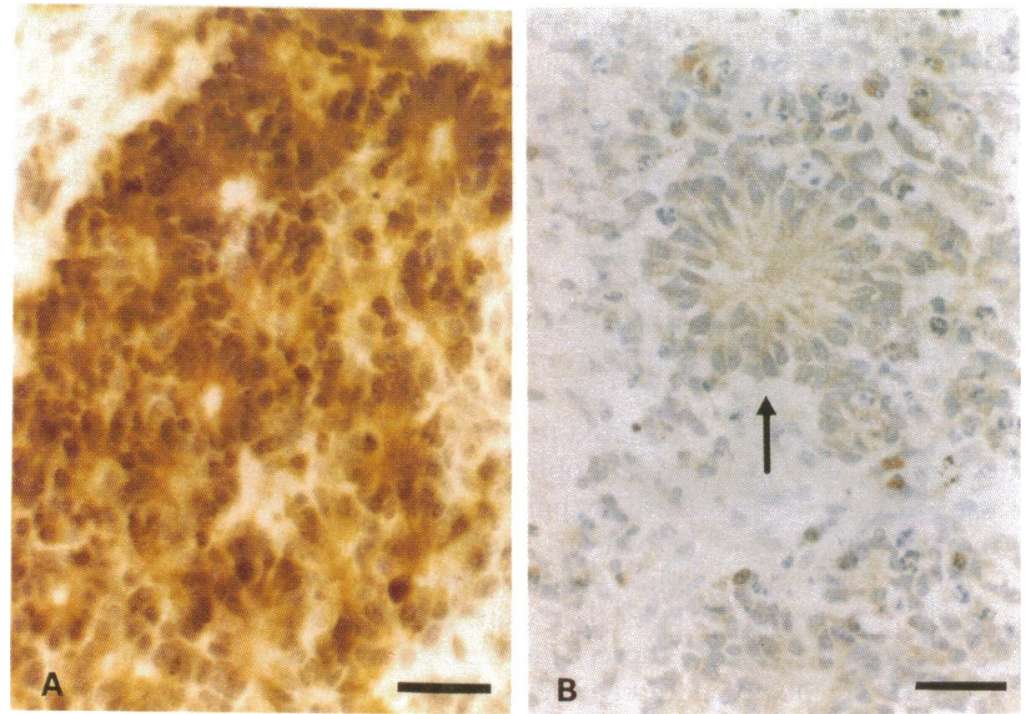

Figure 2 Differentiated retinoblastoma cells immunostained strongly with neuron specific enolase in Flexner-Wintersteiner rosettes $(A)$ and weakly in Homer-Wright rosettes (arrow, $B$ ) (haematoxylin and eosin, bar indicates $100 \mu \mathrm{m}$ ).

oval nuclei, a variable amount of cytoplasm, and long thin multiprocesses (Fig 5A). They were embedded in the tumour mass and their cell processes extended through the tumour. The former GFAP positive cells were interpreted as neoplastic glial cells, while the latter were considered to be reactive astrocytes. In 77 of 100 retinoblastomas $(77 \%)$, we found a great variety of GFAP positive glial cells ranging from perivascular to scattered reactive, or even to extensive gliosis formed by Muller's cells. Glial cells in recognisable areas of optic nerve or retina seemed to proliferate in the tumour, with some of these foci being noncontiguous to the retina. Immunostaining for GFAP was not found in rosettes.

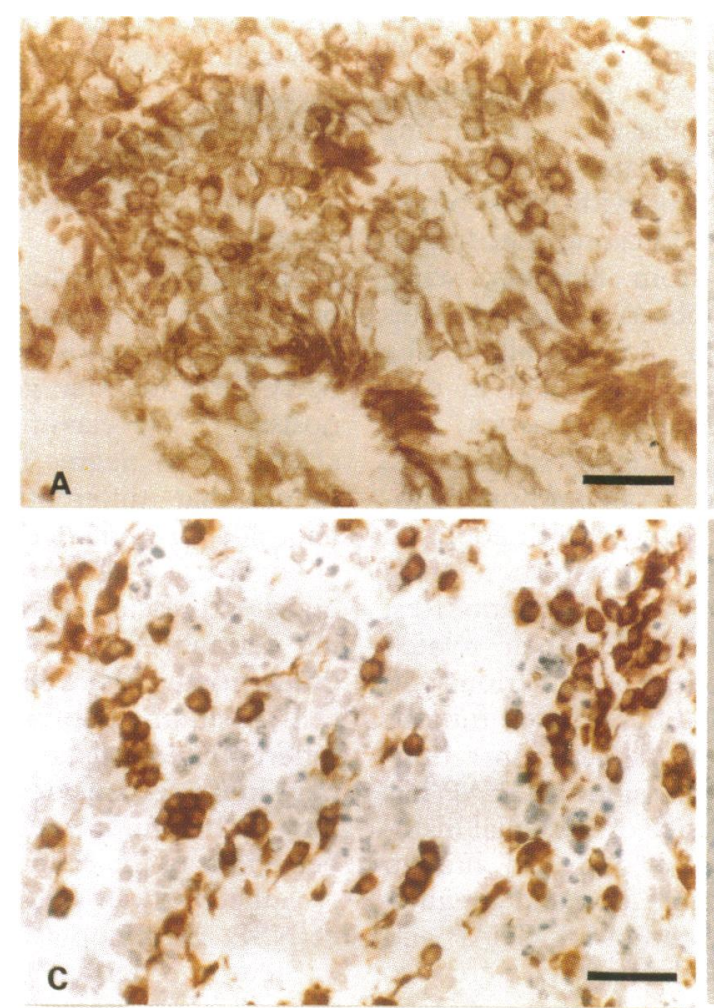

In some astrocytic gliomas $(16 / 18,88.9 \%)$ and medulloblastomas $(4 / 15,26 \cdot 7 \%)$, well differentiated cells exhibiting features of neoplasm were GFAP positive (Figs $4 B$ and C, respectively), resembling those in retinoblastomas. A positive tumour cell spectrum ranging from well differentiated cells to poorly differentiated ones was exhibited. Reactive astrocytes in astrocytic gliomas (Fig 5C) were similar to those in retinoblastomas. In control specimens of the normal brain, astrocytes contained GFAP while oligodendrocytes and neurons did not.

\section{S-100 PROTEIN}

The results with this antibody were basically similar to those with GFAP in retinoblastoma and normal retina, but with negative staining of the Muller's cells. Although the intensity of immunostaining varied, tumour cells expressing S-100 were found in eight of 100 retinoblastomas $(8 \%)$ in undifferentiated areas (Fig 4D), including two positive for GFAP as well. These cells had the same morphology as well differentiated tumour cells in astrocytic gliomas (Fig 4E) and medulloblastomas (Fig 4F). We also noted that cells expressing $\mathrm{S}-100$ were reactive astrocytes in retinoblastomas (Fig 5B).

\section{Discussion}

The histogenesis of retinoblastoma has been controversial for more than a century. When applied polyclonal antibodies were detected by a sensitive immunohistochemical method, we found evidence of neuronal and glial differentiation in retinoblastomas.

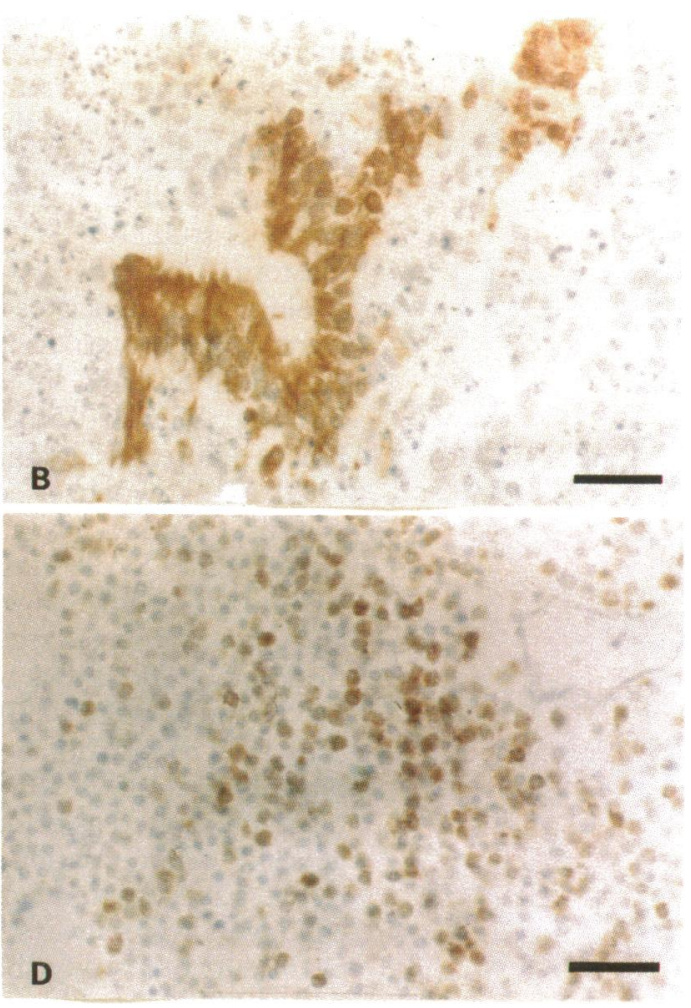

Figure 3 Cells without rosette formation but neuron specific enolase positive in retinoblastoma included well differentiated ones resembling photoreceptors in the outer nuclear layer $(A)$, those tending to form rosettes $(B)$, scattered cells with a few cytoplasmic processes (C), and poorly differentiated small round cells (D) (haematoxylin and eosin, bar indicates $100 \mu \mathrm{m})$. 
Table 3 Relations between neuron specific enolase (NSE) expression and clinicopathological features in 100 retinoblastomas

\begin{tabular}{|c|c|c|c|c|c|}
\hline Clinicopathological classification & $N E$ & $L E$ & $H E$ & No & p Value \\
\hline \multicolumn{6}{|l|}{ Histopathological type } \\
\hline Differentiated & 2 & 18 & 10 & 30 & \multirow{2}{*}{$<0.01$} \\
\hline Undifferentiated & 41 & 28 & 1 & 70 & \\
\hline \multicolumn{6}{|l|}{ Choroidal invasion } \\
\hline With & 13 & 2 & 0 & 15 & \multirow{2}{*}{$<0.01$} \\
\hline \multirow{2}{*}{\multicolumn{6}{|c|}{ Optic nerve invasion }} \\
\hline & & & & & \\
\hline With & 12 & 2 & 0 & 14 & \multirow{2}{*}{$<0.01$} \\
\hline \multicolumn{5}{|l|}{ Age (years) } & \\
\hline $\begin{array}{l}<4 \\
\geqslant 4\end{array}$ & 26 & $\begin{array}{r}37 \\
9\end{array}$ & 10 & 73 & $<0.01$ \\
\hline \multicolumn{6}{|l|}{ Sex } \\
\hline Male & 25 & 22 & 5 & 52 & \multirow{2}{*}{$>0.05$} \\
\hline Female & 18 & 24 & 6 & 48 & \\
\hline \multicolumn{6}{|l|}{ Growth pattern } \\
\hline Endophytum & 12 & 19 & 3 & 34 & \multirow{3}{*}{$>0.05$} \\
\hline Exophytum & 17 & 20 & 6 & 43 & \\
\hline Diffuse infiltration & 14 & 7 & 2 & 23 & \\
\hline
\end{tabular}

$\mathrm{NE}=$ no expression, no positive staining; $\mathrm{LE}=$ low expression, distribution of positive cells in les than $50 \%$ of the specimen; $\mathrm{HE}=$ high expression, distribution of positive cells in more than $50 \%$ of the specimen. ${ }^{\star}$ Based on the $\chi^{2}$ test.

The neuronal and glial markers of NSE, GFAP, and S-100 have been studied critically with various cell types and tumours. NSE, also called gamma-gamma enolase, is normally found in neurons and neuroendocrine cells of the APUD (amine precursor uptake and decarboxylation) system. ${ }^{2021}$ In this study, we found identical positive staining in normal retina and most of the differentiated retinoblastoma cells. Neurons and their cell processes in the outer and inner nuclear layer, ganglion cells in normal retina, as well as tumour cells forming areas of rosettes in retinoblastomas were NSE positive. Cells forming FlexnerWintersteiner rosettes were presumed to represent neuronal differentiation. ${ }^{45}$ Other NSE positive cells without apparent rosette formation showed various degrees of differentiation; some of them resembled photoreceptors in the outer nuclear layer, representing considerable differentiation in undifferentiated retinoblastomas. Furthermore, none of the glial cells surrounding blood vessels were immunostained. These findings are in close agreement with those of the previous studies, ${ }^{6-91516}$ indicating that retinoblastoma may derive from neurons, while Molnar and associates observed that rosettes were stained weakly or not at all. ${ }^{14}$ The equivocal findings in the retina and in cells forming Flexner-Wintersteiner rosettes may reflect differences among antibody specificities.

GFAP is widely used as an immunohistochemical marker for astrocytes and neoplastic astrocytes. $^{22}$ S-100 has been shown to be a useful marker for Schwann cells, melanocytes, and glial cells, as well as for their related tumours. ${ }^{23}$ GFAP has been found variously in reactive glial cells, ${ }^{714}$ undifferentiated tumour cells, ${ }^{1516}$ or has not been detected in retinoblastomas at all. ${ }^{12}{ }^{13}$ Expression of GFAP has been interpreted as evidence of astroglial histogenesis, differentiation, or both. In human retina, glial cells in the nerve fibre and ganglion cell layers were always stained for GFAP and S-100. In our study, both markers were also detectable in retinoblastoma.

Two crucial questions must be addressed: (1) What are the criteria to identify positive glial cell types? (2) Are the positive glial cells differentiated from a precursor cell in retinoblastoma, or do they originate from a residual glial tissue as a reactive glial proliferation? Based on the cytological features of scanty cytoplasm and short processes, the location of the glial cells within the tumour, and the distance from uninvolved retina, we consider that the positive glial cells separated from normal components of the retina and developed from tumour. Also, the neoplastic glial cells in retinoblastoma resembled well differentiated tumour cells of astrocytic gliomas and medulloblastomas, suggesting an astroglial, rather than a Muller's cell, ${ }^{24}$ differentiation. However, the majority of the GFAP positive glial cells displayed features of reactive glial cells that were associated with blood vessels. These cells seemed to derive from astrocytes and Muller's cells in optic nerve and/or normal retina and then proliferate within the tumour. Hence, glial elements in retinoblastomas may represent a glial differentiation along a glial direction and a secondary proliferation of the retinal glial cells in response to tumour growth.

Cells containing GFAP and $\mathrm{S}-100$ in retinoblastoma possessed the morphological attributes of neoplastic cells, but were seldom present in large numbers and lacked the range of stages from mature to anaplastic transition. To our knowledge, there are no well documented reports of an immunopathological study of differentiation of glial elements in retinoblastoma. In addition, the reason that astrocytes preferentially express S-100 in formalin fixed and paraffin embedded materials may be that GFAP is not easily detectable, but often needed for optimal detection in immunohistochemical studies. ${ }^{13} 15$

The study of medulloblastomas with NSE and GFAP or S-100 has shown components of glia and neuron in the tumour, suggesting the possibility of simultaneous neuronal and glial differentiation. The significance of neoplastic neuronal and glial cells within retinoblastomas is analogous to medulloblastomas to some extent. ${ }^{325}$

Clinically, rosette formation in retinoblastoma is an important indicator for a favourable prognosis. ${ }^{26-29}$ It is evident that optic nerve invasion greatly worsens the prognosis. ${ }^{27-29}$ We classified 100 retinoblastomas according to degree of NSE expression. We found that differentiated tumours without choroidal or optic nerve invasion in patients of younger age $(<4$ years old) had a significantly higher expression of NSE than did the remaining retinoblastomas. Expression of NSE in differentiated as well as in undifferentiated cells, including photoreceptor-like cells, poorly differentiated cells, or even bipolar-like cells, ${ }^{11}$ may indicate considerable differentiation and may be helpful in predicting benign biological behaviour of the retinoblastoma.

Collectively, a well documented expression of NSE in retinoblastoma favours a neuronal or neuroectodermal lineage. Some glial cells may be incorporated into retinoblastoma from the retina as a secondary response to tumour growth. Tumour cells containing GFAP and S-100 show similar glial differentiation in 

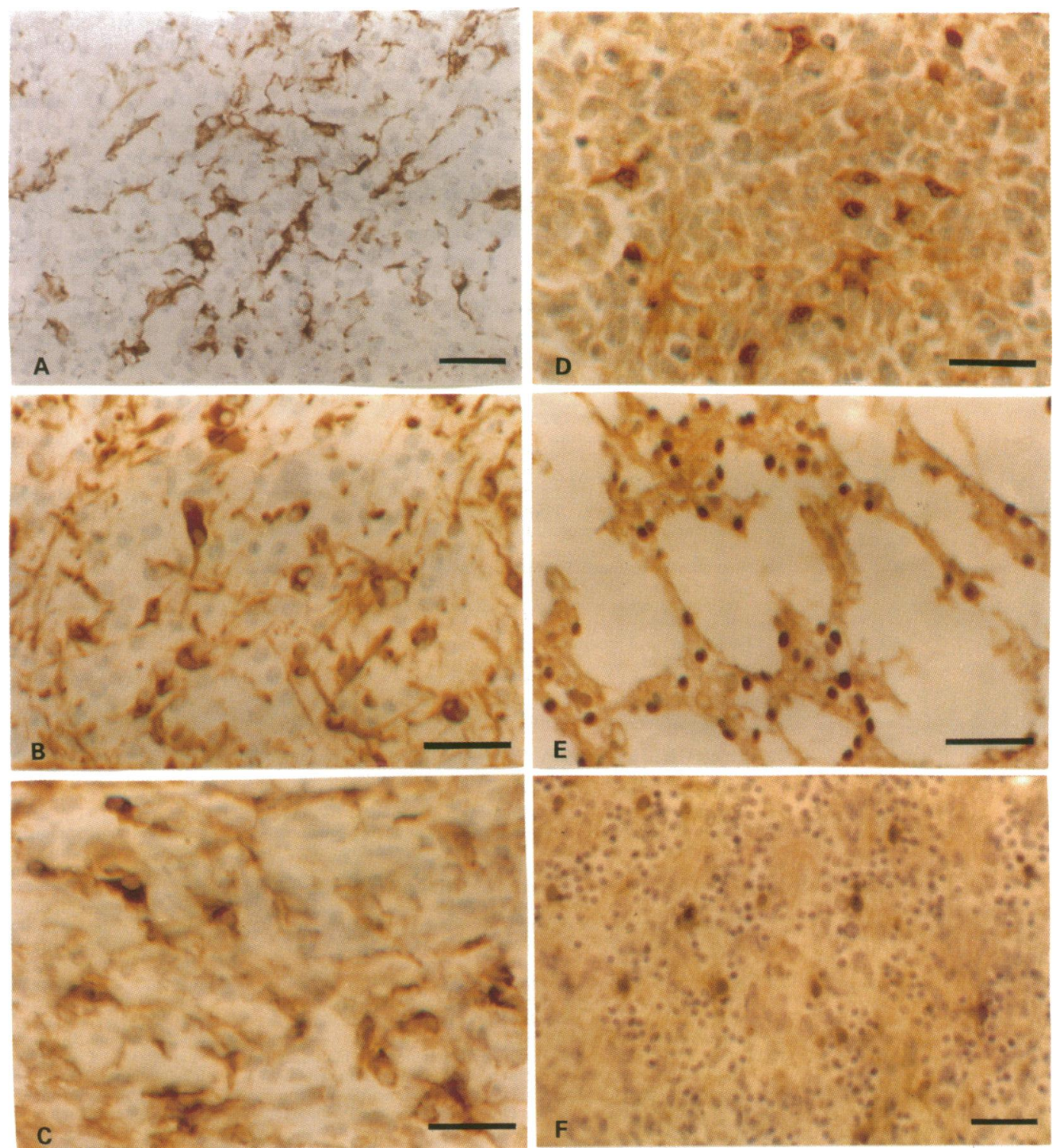

Figure 4 Histopathologic comparison of neoplastic cells immunostained with two glial markers of glial fibrillary acidic protein (GFAP) and S-100 protein (S-100) in retinoblastoma, astrocytic glioma, and medulloblastoma. Neoplastic cells stained with GFAP have a round hyperchromatic nucleus, scanty cytoplasm, and a few short thick processes in

retinoblastoma $(A)$, resembling those in well differentiated astrocytic glioma $(B)$ and medulloblastoma $(C)$. Neoplastic cells positive for S-100 in retinoblastoma (D) have the same morphology as those in well differentiated astrocytic glioma $(E)$ and medulloblastoma $(F)$ (haematoxylin and eosin, bar indicates $100 \mu \mathrm{m}$ ).
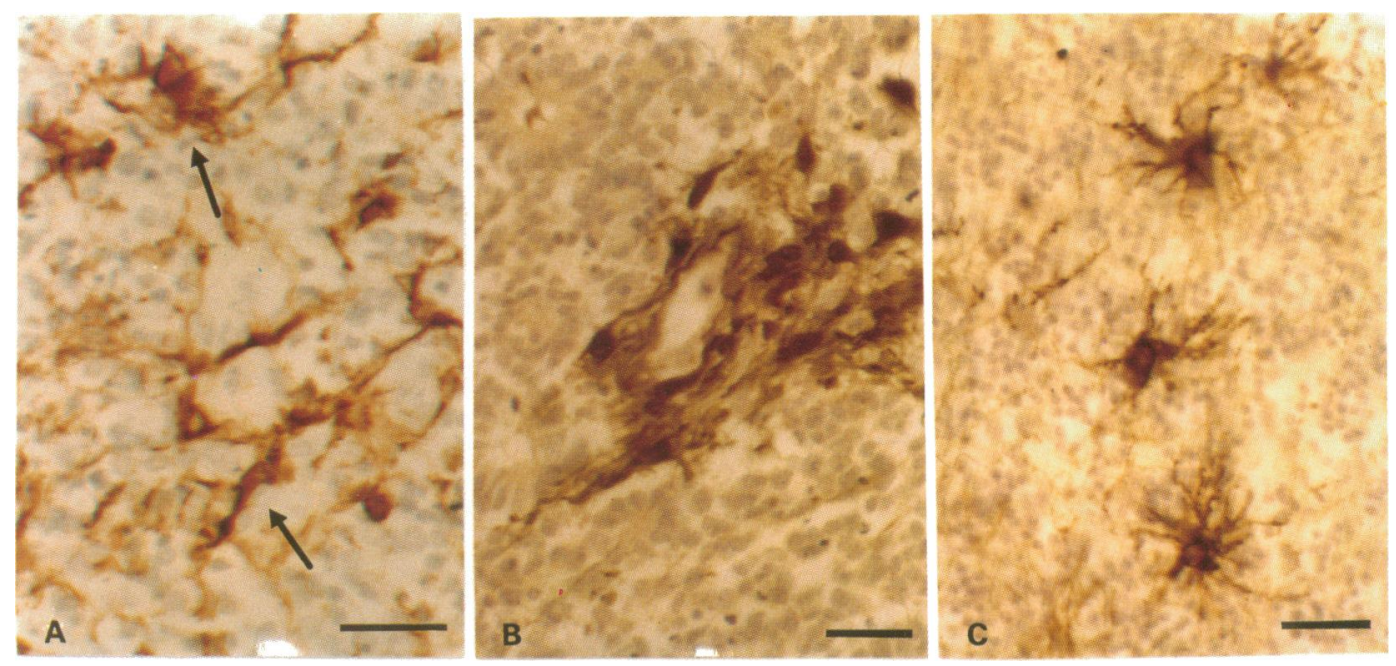

Figure 5 Reactive astrocytes stained with glial fibrillary acidic protein (GFAP) (arrows) and S-100 in retinoblastoma ( $A$ and $B$, respectively) are closely related to blood vessels. These cells are much alike reactive astrocytes stained with GFAP in astrocytic glioma (C), having an oval nucleus, a variable amount of cytoplasm, and long thin multiprocesses (haematoxylin and eosin, bar indicates $100 \mu \mathrm{m}$ ). 
retinoblastoma and either type of brain tumour. These results support the notion that retinoblastoma probably arises from primitive bipotential or multipotential cells with partial retention of neuronal and glial characteristics.

Presented in part at 4th National Symposium on Ophthalmic Pathology, Oing Dao, China, 1990.

The authors have no proprietary interest in any subject matter discussed in the article.

1 Virchow R. Die krankhaften Geschwulste. Vol 2. Berlin: Hirschwald, 1864: 151.

2 Flexner S. A peculiar glioma (neuroepithelioma?) of the retina. Bull fohns Hopkins Hosp 1891; 2: 115-9.

3 Bailey P, Cushing H. Medulloblastoma cerebella: common type of midcerebellar glioma of the childhood. common type of midcerebellar gliom

4 Tso MOM, Zimmerman LE, Fine BS. The nature of retinoblastoma. 1: Photoreceptor differentiation: a clinica and histologic study. Am $\mathcal{f}$ Ophthalmol 1970; 69: 339-49.

5 Tso MOM, Fine BS, Zimmerman LE. The nature of retinoblastoma. 2: Photoreceptor differentiation: an electron microscopic study. Am $\mathcal{F}$ Ophthalmol 1970; 69: 350-9.

6 Nakajima T, Kameya T, Tsumuraya M, Shimosato Y, Kato $\mathrm{K}$. Enolase distribution in human brain tumors, retinoblastomas and pituitary adenomas. Brain Res 1984; 308: $215-22$.

7 Takayama S, Yamamoto M. 27 cases of retinoblastoma: pathological and immunohistological studies. Nippon Ganka Gakkai Zasshi 1985; 89: 797-803.

8 Kivela T. Neuro-specific enolase in retinoblastoma: an immunohistochemical study. Arch Ophthalmol 1986; 64 19-25.

9 Perentes E, Herbort CP; Rubinstein LJ, Herman MM, Uffer S, Donoso LA, et al. Immunohistochemical characterization of human retinoblastomas in situ with multiple markers. Am 7 Ophthalmol 1987; 103: 647-58.

10 Tarlton JF, Easty DL. Immunohistological characterization of retinoblastoma and related ocular tissue. $\mathrm{Br} f$ of retinoblastoma and relate

11 He W, Hashimoto H, Tsuneyoshi M, Enjoji M, Inomata H. A reassessment of histologic classification and an immunohistochemical study of 88 retinoblastomas: special reference to the advent of bipolar-like cells. Cancer 1992; 70: 2901-8.

12 Lane JC, Klintworth GK. A study of astrocytes in retinoblastomas using the immunoperoxidase technique and antibodies to glial fibrillary acidic protein. $A m \mathcal{F}$ Ophthalmol 1983; 95: 197-207.

13 Kivela T, Tarkkanen A, Virtanen I. Intermediate filaments in the human retina and retinoblastoma: an immunohistochemical study of vimentin, glial fibrillary acidic protein and neurofilaments. Invest Ophthalmol Vis Sci 1986; 27 1075-84.
14 Molnar ML, Stefansson K, Marton LS, Tripathi RS, Molnar GK. Immunohistochemistry of retinoblastomas in humans. Am $\mathcal{f}$ Ophthalmol 1984; 97: 301-7.

15 Terenghi G, Polak JM, Ballesta J, Cocchia D, Michetti F, Dahl $\mathrm{D}$, et al. Immunohistochemistry of neuronal and glial markers in retinoblastoma. Virchows Arch A Pathol Anat Histopathol 1984; 404: 61-73.

16 Messmer EP, Font RL, Kirkpatrick JB, Hopping W. Immunohistochemical demonstration of neuronal and Immunohistochemical demonstration of neuronal and astrocytic differentiation

17 Shuangshoti S, Chaiwun B, Kasantikul V. A study of 39 retinoblastomas with particular reference to morphology, cellular differentiation and tumor origin. Histopathology 1989; 15: 113-24.

18 Gonzalez-Fernandez F, Lopes MBS, Garcia-Fernandez JM, Foster RG, De Grip WJ, Rosemberg S, et al. Expression of developmentally defined retinal phototypes in the histogenesis of retinoblastoma. Am $\mathcal{f}$ Pathol 1992; 141: 363-75.

19 Hsu SM, Raine L, Franger H. Use of avidin-biotin peroxidase complex (ABC) in immunoperoxidase techniques: comparison between $\mathrm{ABC}$ and unlabeled antibody (PAP) procedures. F Histochem Cytochem 1981; 29: 577-80.

20 Schmechel D, Marangos PJ, Zis AP, Brightman M, Goodwin FK. Brain enolases as specific markers of neuronal and glial cells. Science 1978; 199: 313-5.

21 Schmechel D, Marangos PJ, Brightman M. Neuron-specific enolase is a molecular marker for peripheral neuroendocrine cells. Nature 1978; 276: 834-6.

22 Eng LF, Rubinstein LJ. Contribution of immunohistochemistry to diagnostic problems of human cerebral tumors. f Histochem Cytochem 1978; 26: 513-22.

23 Cochran AJ, Holland GN, Wen DR, Herschman HR, Lee WR, Foos RY, et al. Detection of cytoplasmic S-100 protein in primary and metastatic intraocular melanomas. Invest Ophthalmol Vis Sci 1983; 24: 1153-5.

24 Craft JL, Sang DN, Dryja TP, Brockhurst RJ, Robinson NL, Albert DM. Glial cell component in retinoblastoma. Exp Eye Res 1985; 40: 647-59.

25 Rubinstein LJ. The cerebellar medulloblastoma: its origin, differentiation, morphological variants, and biological behavior. In: Vinken PJ, Bruyn GW, eds. Handbook of clinical neurology. Amsterdam: North-Holland, 1974: clinical $167-93$.

26 Tso MOM, Zimmerman LE, Fine BS, Ellsworth RM. A cause of radioresistance in retinoblastoma: photoreceptor differentiation. Trans Am Acad Ophthalmol Otolaryngol 1970; 74: 959-69.

27 Tsukahara I. A histopathologic study on the prognosis and radiosensitivity of retinoblastoma. Arch Ophthalmol 1960; 63: 131-4.

28 Yanoff M, Fine BS. Retinoblastoma and pseudoglioma. In: Yanoff M, Fine BS, eds. Ocular pathology. 3rd ed. Philadelphia: JB Lippincott, 1989: 684-94.

29 Shields JA, Augsburger JJ. Current approaches to the diagnosis and management of retinoblastoma. Surv Ophthalmol 1981; 25: 347-72. 